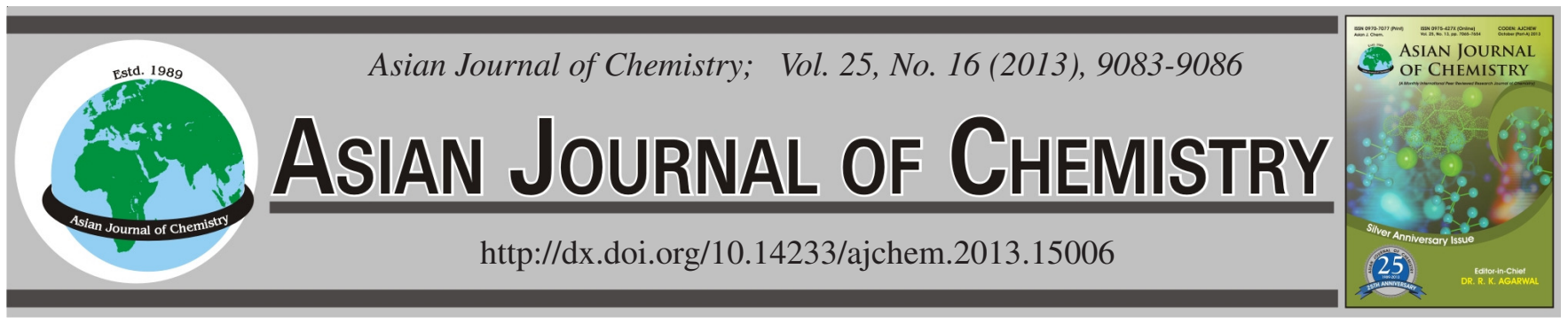

\title{
Series of Azobenzothiazole-Based Initiators for Atom Transfer Radical Polymerization of Methyl Methacrylate
}

\author{
Menguun Jiang ${ }^{1,2,3}$, Gangming Cai ${ }^{1}$, Yaoyuan Zhou ${ }^{1}, \mathrm{XiaObo} \mathrm{Gu}^{1}$ and Rongunn Zhang ${ }^{1, *}$
}

${ }^{1}$ Key Laboratory of Nuclear Medicine, Ministry of Health, Jiangsu Key Laboratory of Molecular Nuclear Medicine, Jiangsu Institute of Nuclear Medicine, 20 Qianrong Road, Wuxi 214063, P.R. China

${ }^{2}$ Department of Clinical Laboratory Science, The First Wuxi Affiliated Hospital of Nanjing Medical University, Wuxi 214023, P.R. China

${ }^{3}$ Wuxi Clinical Science Research Institute, Wuxi 214023, P.R. China

*Corresponding author: E-mail: zhangrongjun@jsinm.org; jiangmengjun@jsinm.org

\begin{abstract}
2-Bromo-2-methyl-propionic acid 4-benzothiazole-2-ylazo-phenyl ester (BPBE), 2-bromo-2-methyl-propionic acid 4-(6-methoxybenzothiazole-2-ylazo)phenyl ester (BPMBE) and 2-bromo-2-methyl-propionic acid 4-(6-nitro-benzothiazole-2-ylazo)phenyl ester (BPNBE) were synthesized and acted as initiators for the heterogeneous atom transfer radical polymerization of methyl methacrylate under copper(I) bromide/2,2'-bipyridine catalytic system, respectively. The azobenzothiazole-based end group of polymethyl methacrylate was characterized via UV-visible spectroscopy. All rates of polymerizations exhibited first-order kinetic with respect to the monomer and a linear increase in the number-average molecular weight with increasing monomer conversion was observed for all these initiation systems. The polydispersity indices of the polymethyl methacrylates were relatively low (1.08-1.37) up to high conversions at $60{ }^{\circ} \mathrm{C}$. Moreover, the initiation systems exhibit a high activity that polymerizations could even be performed at ambient temperature $\left(30^{\circ} \mathrm{C}\right)$.
\end{abstract}

Key Words: Azobenzothiazole, Atom transfer radical polymerization, Gel permeation chromatography, UV-visible spectroscopy. ᄂ - - - - - - - - - - - - - - - - - - - - - - - - -

\section{INTRODUCTION}

Polymeric materials incorporating azobenzene moieties have been extensively studied due to their potential technological application, such as optical storage ${ }^{1}$, optical switching ${ }^{2}$, liquid crystal alignment ${ }^{3}$ and optical diffraction devices ${ }^{4,5}$. Various methods have been developed to attach azobenzene moieties to the side chains ${ }^{6-10}$, main chain ${ }^{11-13}$ or chain end of polymers $^{14,15}$. Especially, azobenzene-terminated polymers have been used as photochromic probes ${ }^{16-18}$. However, little attention has been paid to the azobenzothiazole-terminated polymers although azobenzothiazole is a promising candidate structure in the design of chromophores with enhanced optical properties $^{19,20}$.

Living and controlled polymerization techniques are appropriate tools to achieve polymers with well-controlled architecture and predictable molecular weight. Among them, atom transfer radical polymerization (ATRP) is an effective method for controlled radical polymerization ${ }^{21,22}$ and the molecular weight and functionality can be well controlled with the method. A wide range of functionality can be introduced into a polymer chain end by using functional initiator if the functional group remains intact during this living radical polymerization. Examples of end-functionalized group through ATRP include di-tert-butyl phthalate ${ }^{23}$, hydroxyl $1^{24}$, dibenzyloxy or dimethylester ${ }^{25}$, tetra-functionalized adamantine etc. ${ }^{26}$.

Our research was focused to report atomic transfer radical polymerization of methyl methacrylate with three initiators with azobenzothiazole (Scheme-I). The aim of this research was to investigate these initiators on the controllability of polymerization and the UV-visible spectra of obtained polymers. The 2-bromo-2-methyl-propionic acid 4-(6-nitrobenzothiazole-2-ylazo)phenyl ester (BPNBE)/copper(I) bromide/2,2'-bipyridine system yielded the lowest rate of polymerization which could be explained by the bad solubility of the initiator. The rates of polymerizations were not affected by electronic effects of the substituted R groups (Scheme-I) remarkably. Moreover, successful incorporation of initiator groups with the polymer chains were confirmed according to the UV-visible spectra.

\section{EXPERIMENTAL}

${ }^{1} \mathrm{H}$ NMR spectra were measured by INOVA $400 \mathrm{MHz}$ NMR spectrometer, $\mathrm{CDCl}_{3}$ or DMSO- $d_{6}$ as solvent and tetramethylsilane (TMS) as the internal standard at ambient 


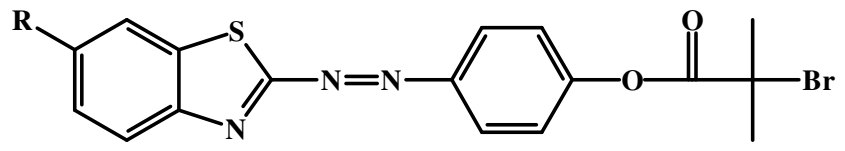

2-Bromo-2-methyl-propionic acid 4-benzothiazole-2-ylazo-phenyl ester (BPBE) $\mathrm{R}=\mathrm{H}$; 2-Bromo-2-methyl-propionic acid 4-(6-methoxy-benzothiazole-2-ylazo)phenyl ester (BPMBE) $\mathrm{R}=\mathrm{CH}_{3} \mathrm{O}$; 2-Bromo-2-methyl-propionic acid 4-(6-nitro-benzothiazole-2-ylazo)phenyl ester (BPNBE) $\mathrm{R}=\mathrm{NO}_{2}$

Scheme-I: Structure of the azobenzothiazole-based initiators

temperature. Molecular weights and the polydispersity relative to PMMA were measured using Waters1515 GPC with THF as a mobile phase at a flow rate of $1 \mathrm{~mL} / \mathrm{min}$ and with column temperature of $30{ }^{\circ} \mathrm{C}$. UV-visible absorption spectra of the polymers and initiator in DMF solutions were determined on a Shimadzu RF540 spectrophotometer.

Methyl methacrylate (98\%; Sinopharm Chemical Reagent Co., Ltd) was purified by extracting with $5 \%$ sodium hydroxide aqueous solution, followed by washing with water and dried with anhydrous sodium sulfate overnight, finally distillated under vacuum. $\mathrm{CuBr}$ (98.5 \%; Sinopharm Chemical Reagent Co., Ltd.) was purified in acetic acid, washed with methanol and dried under vacuum to afford a white powder. Benzothiazole2-ylamine (99\%; Ninghai Shangfeng Chemical Reagent Co., Ltd.) and 6-methoxy-benzothiazole-2-ylamine (99\%; Ninghai Shangfeng Chemical Reagent Co., Ltd) were used as received. 2-Bromo-2-methylpropionyl bromide (97 \%; Alfa Aesar) was used as received. 6-Nitro-benzothiazole-2-ylamine and 4-(6nitro-benzothiazole-2-ylzao)-phenol were synthesized according to the reported procedure ${ }^{27,28}$. All other reagents and solvents were analytic pure and used as received.

General procedure for synthesis of 4-benzothiazole-2ylzao-phenol and 4-(6-methoxy-benzothiazole-2-ylzao)phenol: The heteroaromatic amine $(0.04 \mathrm{~mol})$ was added to a mixture of distilled water $(32 \mathrm{~mL})$, concentrated $\mathrm{H}_{2} \mathrm{SO}_{4}(20$ $\mathrm{mL})$ and formic acid $(8 \mathrm{~mL})$. A solution of sodium nitrite $(0.044$ $\mathrm{mol})$ in distilled water $(20 \mathrm{~mL})$ was prepared in a test tube. Sodium nitrite solution was added dropwise to the acidic solution of amine over $1 \mathrm{~h}$ at $0-2{ }^{\circ} \mathrm{C}$. The mixture was stirred at $0-2^{\circ} \mathrm{C}$ for $45 \mathrm{~min}$. Phenol $(0.04 \mathrm{~mol})$ was dissolved in ethanol $\left(20 \mathrm{~mL}\right.$ ) and cooled to $0^{\circ} \mathrm{C}$. Phenol solution was added slowly to the diazonium salt solution at $0-5^{\circ} \mathrm{C}$. The resultant colored mixture was stirred for $24 \mathrm{~h}$ at $0-5^{\circ} \mathrm{C}$. The solution was filtered and the obtained crude product was recrystallized for two times from ethanol.

4-Benzothiazole-2-ylzao-phenol: Orange powder. Yield: $38 \% .{ }^{1} \mathrm{H}$ NMR (DMSO- $\left.d_{6}, \delta\right): 10.97(\mathrm{~s}, 1 \mathrm{H}), 8.12-8.10$ (m, 2H), 7.96-7.94 (d, 2H), 7.60-7.52 (m, 2H), 7.05-7.03 (d, 2H).

4-(6-Methoxy-benzothiazole-2-ylzao)-phenol: Henna powder. Yield: $46 \%$. ${ }^{1} \mathrm{H}$ NMR (DMSO- $\left.d_{6}, \delta\right): 10.86(\mathrm{~s}, 1 \mathrm{H})$, 8.01-7.98 (d, 1H), 7.92-7.89 (d, 2H), 7.66 (s, 1H), 7.19-7.15 (d, 1H), 7.03-7.00 (d, 2H), 3.88 (s, 3H).

General procedure for synthesis of BPBE, BPMBE and BPNBE: The phenol derivates $(0.01 \mathrm{~mol})$ was dissolved in a mixture of triethylamine $\left(\mathrm{Et}_{3} \mathrm{~N}, 0.02 \mathrm{~mol}\right)$ and freshly distilled tetrahydrofuran (THF, $80 \mathrm{~mL}$ ). This solution was then cooled in an ice-water bath with vigorous stirring. Then, a solution containing 2-bromo-2-methylpropionyl bromide $(0.01 \mathrm{~mol})$ and freshly dried THF $(20 \mathrm{~mL})$ was added to the above mixture by a dropping funnel under a nitrogen atmosphere. After $1 \mathrm{~h}$, the ice-water bath was removed and the reaction was allowed to continue for $24 \mathrm{~h}$ at room temperature. The solution was filtered and poured into a large amount of water. The precipitated product was washed by ethanol $(95 \%)$ and recrystallized from trichloromethane and petroleum ether $\left(60-90{ }^{\circ} \mathrm{C}\right)$.

2-Bromo-2-methyl-propionic acid 4-benzothiazole-2ylazo-phenyl ester (BPBE): Yellow powder. Yield: $73 \% .{ }^{1} \mathrm{H}$ NMR $\left(\mathrm{CDCl}_{3}, \delta\right): 8.21-8.18(\mathrm{~d}, 1 \mathrm{H}), 8.17-8.14(\mathrm{~d}, 2 \mathrm{H}), 7.93-$ $7.90(\mathrm{~d}, 1 \mathrm{H}), 7.58-7.47$ (m, 2H), 7.39-7.36 (d, 2H), 2.10 (s, $6 \mathrm{H})$.

2-Bromo-2-methyl-propionic acid 4-(6-methoxy-benzothiazole-2-ylazo)phenyl ester (BPMBE): Brown powder. Yield: $66 \%$. ${ }^{1} \mathrm{H}$ NMR $\left(\mathrm{CDCl}_{3}, \delta\right): 8.14-8.05(\mathrm{~m}, 3 \mathrm{H}), 7.37-$ 7.32 (m, 3H), 7.16-7.12 (d, 1H), 3.93 (s, 3H), 2.10 (s, 6H).

2-Bromo-2-methyl-propionic acid 4-(6-nitro-benzothiazole-2-ylazo)phenyl ester (BPNBE): Brown powder. Yield: $60 \%$. ${ }^{1} \mathrm{H}$ NMR (DMSO- $d_{6}, \delta$ ): 9.09 (s, $\left.1 \mathrm{H}\right), 8.42-8.20$ (m, 2H), 7.95-7.93 (d, 2H), 7.20-7.17 (d, 2H), 2.08 (s, 6H).

General procedure for polymerizations: Initiator, $\mathrm{CuBr}$, BPY, MMA and cyclohexanone were mixed in a round-bottomed flask. The flask was sealed and cycled between vacuum and $\mathrm{N}_{2}$ for three times. The polymerization was processed at a predetermined temperature under $\mathrm{N}_{2}$. Samples for conversion and molecular weight analysis were taken at regular intervals, dissolved in THF and precipitated into a large mount of methanol/ $\mathrm{HCl}(100 / 0.5, \mathrm{v} / \mathrm{v})$. The precipitation was filtrated and dried under vacuum.

\section{RESULTS AND DISCUSSION}

Atomic transfer radical polymerization (ATRP) of methyl methacrylate using azobenzothiazole-based initiators: Atom transfer radical polymerization of methyl methacrylate using three different azobenzothiazole-based initiators was investigated and the results were shown in Figs. 1-3. According to Fig. 1, the polymerization of MMA proceeded through firstorder kinetics with respect to monomer concentration for all the polymerizations. The number average molecular weight $\left(M_{n}\right)$ increased with the monomer conversion (Fig. 2), which indicated a constant concentration of growing chains throughout the reaction. Polydispersities remained relatively low (1.081.37) during polymerization (Fig. 3). However, the polymerizations showed some deviations in molecular weight from the theoretical $\mathrm{M}_{\mathrm{n}}$ (Fig. 2) and instead of a continuing decrease in polydispersity with conversion (as often observed in other ATRP systems), a continuing increase in polydispersity occurred at higher conversions (Fig. 3). The deviations were presumably due to an unidentified transfer process and slower initiation $^{29}$. The polymerizations initiated by BPNBE were much slower than those of the other initiation systems due to the worse solubility of BPNBE. The rate of polymerization initiated by BPBE was near to that of polymerization initiated by BPMBE, which suggested that little influence was imposed on the polymerizations by $\mathrm{R}$ group (Scheme-I). It could be explained by the long distance between the halogen and $\mathrm{R}$ groups.

Atomic transfer radical polymerization of methyl methacrylate at ambient temperature: The ATRP of MMA bearing 


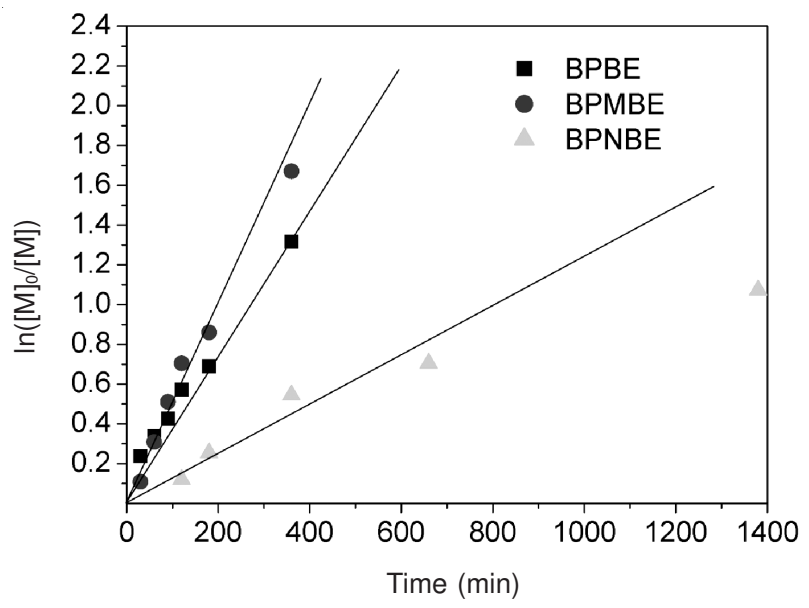

Fig. 1. Kinetic plots for ATRP of MMA with azobenzothiazole-based initiators BPBE, BPMBE and BPNBE in cyclohexanone solutions (mcyclohexanone : $\left.\mathrm{m}_{\text {MMA }}=2: 1\right)$ at $60{ }^{\circ} \mathrm{C}\left([\mathrm{MMA}]_{0} /[\text { initiator }]_{0} /\right.$ $\left.[\mathrm{CuBr}]_{0} /[\mathrm{Bpy}]_{0}=200 / 1 / 2 / 3\right)$

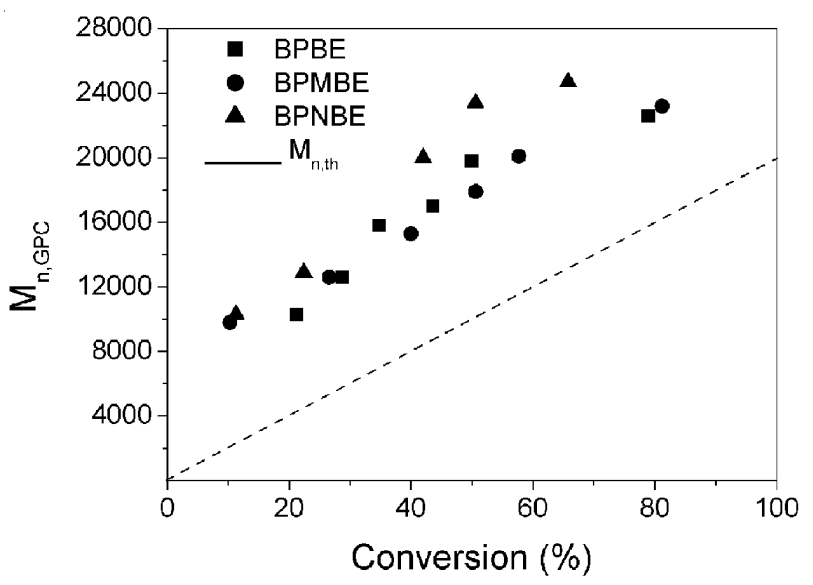

Fig. 2. Dependence of $\mathrm{M}_{\mathrm{n}}$, GPC on conversion for ATRP of MMA with azobenzothiazole-based initiators BPBE, BPMBE and BPNBE in cyclohexanone solutions (mcyclohexanone : $\mathrm{m}_{\mathrm{MMA}}=2: 1$ ) at $60^{\circ} \mathrm{C}$ $\left([\mathrm{MMA}]_{0} /[\text { initiator }]_{0} /[\mathrm{CuBr}]_{0} /[\mathrm{Bpy}]_{0}=200 / 1 / 2 / 3\right)$

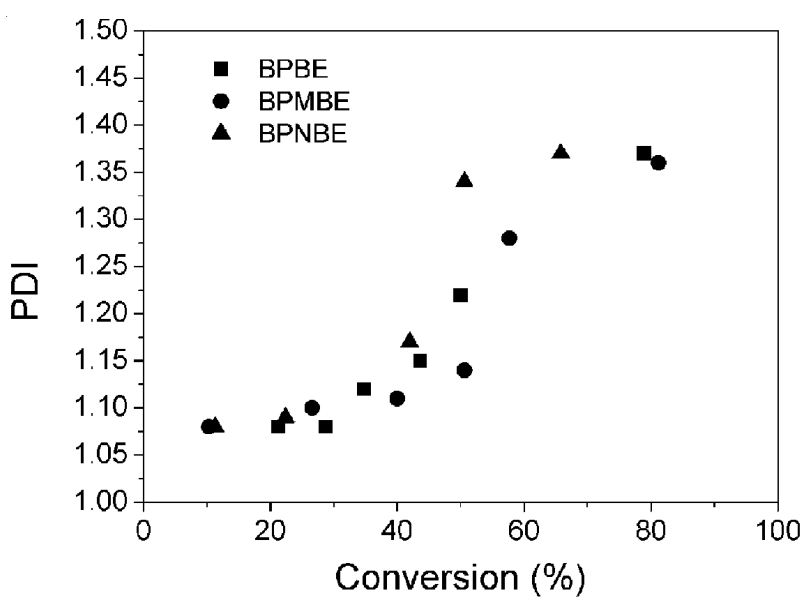

Fig. 3. Dependence of PDI on conversion for ATRP of MMA with azobenzothiazole-based initiators BPBE, BPMBE and BPNBE in cyclohexanone solutions (mcyclohexanone: $\mathrm{m}_{\mathrm{MMA}}=2: 1$ ) at $60{ }^{\circ} \mathrm{C}$ $\left([\mathrm{MMA}]_{0} /[\text { initiator }]_{0} /[\mathrm{CuBr}]_{0} /[\mathrm{Bpy}]_{0}=200 / 1 / 2 / 3\right)$

azobenzothiazole-based groups could even be proceeded at ambient temperature $\left(30{ }^{\circ} \mathrm{C}\right)$ and the results were shown in Table-1. The weak $\mathrm{C}-\mathrm{Br}$ bond of initiators was responsible for the fast rate of polymerization in $\mathrm{Br}-\mathrm{iB} / \mathrm{CuBr}$ system since radicals were easily generated during the activation process ${ }^{29}$. The fast rate of polymerization of was also attributed to the fact that the substituents ester groups containing azobenzothiazole contributed to the stabilization of the generated radicals ${ }^{30}$. In addition, polydispersity at $30{ }^{\circ} \mathrm{C}$ became lower than those at $60{ }^{\circ} \mathrm{C}$, which might be caused by low radical concentration at lower temperature ${ }^{31}$.

\begin{tabular}{|c|c|c|c|c|}
\hline \multicolumn{5}{|c|}{$\begin{array}{c}\text { TABLE-1 } \\
\text { ATRP OF MMA WITH BENZOTHIAZOLE-BASEDINITIATORS } \\
\text { BPBE, BPMBE AND BPNBE IN CYCLOHEXANONE } \\
\text { SOLUTIONS }\left(\mathrm{m}_{\text {cycldexanone }}: \mathrm{m}_{\mathrm{MMA}}=2: 1\right) \text { at } 30^{\circ} \mathrm{C} \\
\left([\mathrm{MMA}]_{0} /[\text { initiator }]_{0} /[\mathrm{CuBr}]_{0} /[\mathrm{Bpy}]_{0}=200 / 1 / 2 / 3\right)\end{array}$} \\
\hline Initiator & Time (h) & Conversion $(\%)$ & $\mathrm{M}_{\mathrm{n}, \mathrm{GPC}}$ & PDI \\
\hline \multirow{2}{*}{ BPBE } & 4 & 11.7 & 9500 & 1.09 \\
\hline & 24 & 75.3 & 25400 & 1.11 \\
\hline \multirow{2}{*}{ BPMBE } & 4 & 16.6 & 9800 & 1.07 \\
\hline & 8 & 39.0 & 17300 & 1.29 \\
\hline \multirow{2}{*}{ BPNBE } & 6 & 7.5 & 8700 & 1.08 \\
\hline & 12 & 23.0 & 16400 & 1.10 \\
\hline
\end{tabular}

UV-visible of initiators and PMM: According to the mechanism of ATRP, initiator group was incorporated at $\alpha$-end of the polymer chain and it could be verified by UV-visible spectra of the azobenzothiazole-based initiators and the corresponding PMMA (Fig. 4). The intensities of the UV absorptions of the initiators were stronger than those of the corresponding PMMA. As report by Gang Wang et al., it was due to the decreased concentration of the chromophores when the initiators were attached to the polymeric chain ${ }^{32}$. The three azobenzothiazole-based initiators exhibited absorption peaks of $\pi-\pi^{*}$ transition at $335-423 \mathrm{~nm}$ and $n-\pi^{*}$ transition at 420 $550 \mathrm{~nm}$ since they were substituted by the different groups.
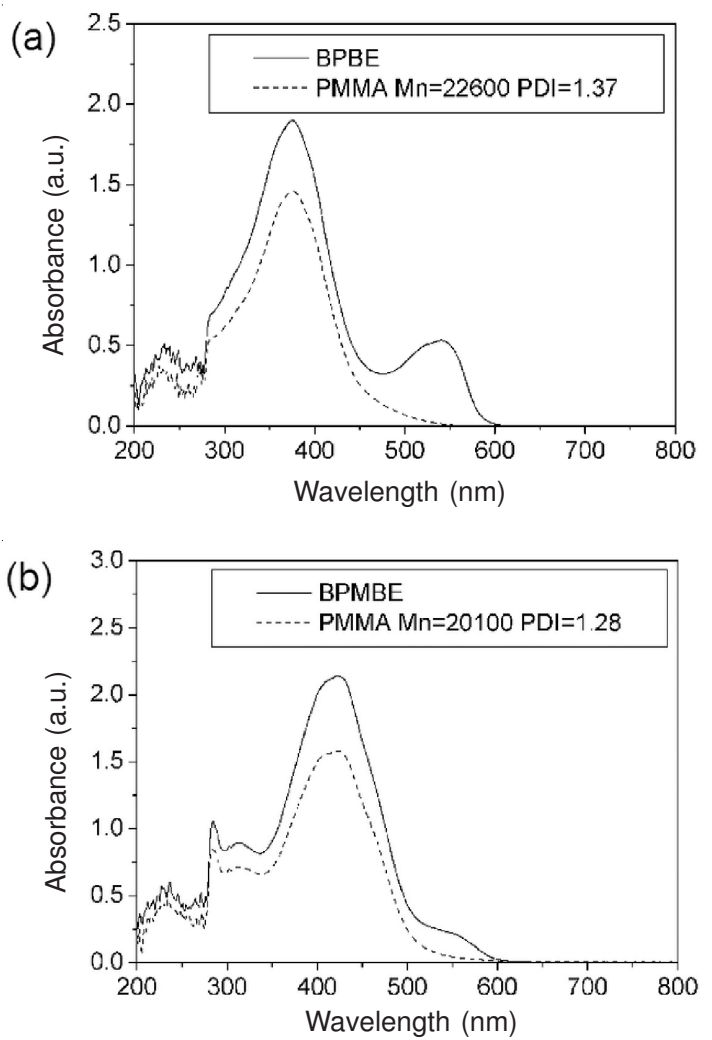


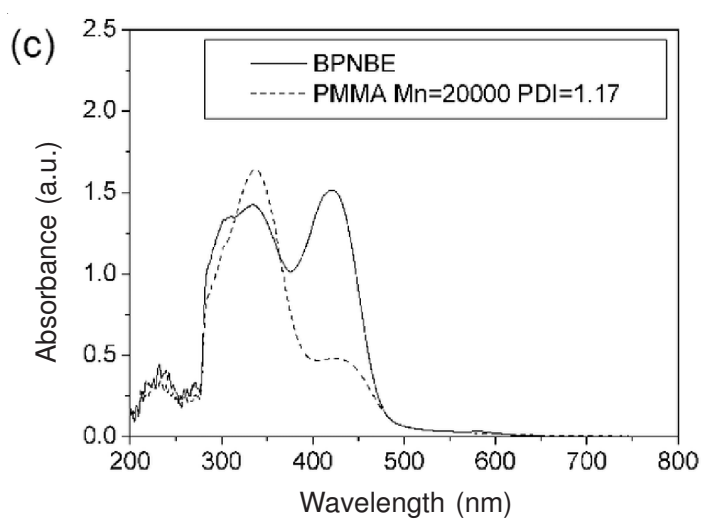

Fig. 4. UV-visible spectra of initiators and corresponding PMMA in DMF solutions $\left(10^{-4} \mathrm{~mol} / \mathrm{L}\right)$

\section{Conclusion}

The polymerizations of MMA with azobenzothiazolebased initiators were well-controlled with the characteristics of controlled/"living" polymerization. The initiators exhibit high activity and the progress could even be performed at ambient temperature $\left(30^{\circ} \mathrm{C}\right)$. The initiator, BPNBE, with the worse solubility afforded relatively slower rate of polymerization. The polymerization rates had little relation with electronic effects of R groups. Polydispersities of PMMA obtained at $30^{\circ} \mathrm{C}$ were lower than those obtained at $60^{\circ} \mathrm{C}$. The process of ATRP was further confirmed through the study of UV-VIS spectra of azobenzothiazole-based initiators and corresponding PMMA.

\section{ACKNOWLEDGEMENTS}

The authors gratefully thank Science Foundation of Health Department of Jiangsu Province (H201226) and Natural Science Foundation of Jiangsu, China (No. BK2010154).

\section{REFERENCES}

1. C.R. Mendonca, A. Dhanabalan, D.T. Balogh, L. Misoguti, D.S. dos Santos, M.A. Pereira-da-Silva, J.A. Giacometti, S.C. Zilio and O.N. Oliveira, Macromolecules, 32, 1493 (1999).

2. A. Natansohn and P. Rochon, Chem. Rev., 102, 4139 (2002).

3. L.T. Thieghi, R. Barberi, J.J. Bonvent, E.A. Oliveira, J.A. Giacometti and D.T. Balogh, Phys. Rev. E, 67, 041701 (2003).
4. P. Rochon, E. Batalla and A. Natansohn, Appl. Phys. Lett., 66, 136 (1995).

5. D.Y. Kim, S.K. Tripathy, L. Li and J. Kumar, Appl. Phys. Lett., 66, 1166 (1995).

6. L. Cui and Y. Zhao, Chem. Mater., 16, 2076 (2004).

7. A.S. Abd-El-Aziz, T.H. Afifi, W.R. Budakowski, K.J. Friesen and E.K. Todd, Macromolecules, 35, 8929 (2002).

8. L.F. Wu, X.L. Tuo, H. Cheng, Z. Chen and X.G. Wang, Macromolecules, 34, 8005 (2001).

9. M. Moniruzzaman, J.S. Christophe and F.F. Gerard, Macromolecules, 37, 2572 (2004).

10. M. Han, S. Morino and K. Ichimura, Macromolecules, 33, 6360 (2000).

11. S. Kumaresan and P. Kannan, J. Polym. Sci. A: Polym. Chem., 41, 3188 (2003).

12. W.W. Li and D.M. Xu, Asian J. Chem., 25, 3625 (2013).

13. T.S. Lee, H. Ahn, W.H. Park, B.H. Sohn, M.J. Kim and D.Y. Kim, J. Polym. Sci. A: Polym. Chem., 41, 1196 (2003).

14. M. Jin, R. Lu, C.Y. Bao, T.H. Xu and Y.Y. Zhao, Polymer, 45, 1125 (2004).

15. V. Percec, H.J. Kim and B. Barboiu, Macromolecules, 30, 8526 (1997).

16. G.S. Kumar and D.C. Neckers, Chem. Rev., 89, 1915 (1989).

17. J. Kronek, J. Luston, F. Bohme and H. Komber, Macromol. Symp., 170, 301 (2001).

18. J. Kronek, J. Luston, F. Bohme and H. Komber, Macromol. Symp., 164, 105 (2001).

19. C. Cojocariu and P. Rochon, J. Mater. Chem., 14, 2909 (2004).

20. R.D. Miller, D.M. Burland, D. Dawson, J. Hedrick, V.Y. Lee, C.R. Moylan, R.J. Twieg, W. Volksen and C.A. Walsh, Polym. Prepr., 35, 122 (1994).

21. J.S. Wang and K. Matyjaszewski, J. Am. Chem. Soc., 117, 5614 (1995).

22. M. Kato, M. Kamigaito, M. Sawamoto and T. Higashimura, Macromolecules, 28, 1721 (1995).

23. B. Moon, T.R. Hoye and C.W. Macosko, Macromolecules, 34, 7941 (2001).

24. T. Sarbu, K.Y. Lin, J. Spanswick and R.R. Gil, Macromolecules, 37, 9694 (2004).

25. S.P. Economopoulos, A.K. Andreopoulou, V.G. Gregoriou and J.K. Kallitsis, Chem. Mater., 17, 1063 (2005).

26. C.F. Huang, H.F. Lee, S.W. Kuo, H.Y. Xu and F.C. Chang, Polymer, 45, 2261 (2004).

27. X.Q. Xia, S.L. Zhao, L. Jiang and Z.T. Wu, Chin. J. Anal. Chem., 26, 103 (1998).

28. M.Y. Goikhman, L.I. Subbotina, I.V. Gofman, A.V. Yakimanskii, A.E. Bursian, V.A. Lukoshkin, G.N. Fedorova, A.V. Sidorovich, O.E. Praslova, N.N. Smirnov, I.V. Abalov and V.V. Kudryavtsev, Russ. Chem. Bull., 54, 1481 (2005).

29. K. Matyjaszewski, J.L. Wang, T. Grimaud and D.A. Shipp, Macromolecules, 31, 1527 (1998).

30. W. Tang and K. Matyjaszewski, Macromolecules, 40, 1858 (2007).

31. X. Yuan, J.M. Lu, Q.F. Xu and L.H. Wang, Polymer, 46, 9186 (2005).

32. G. Wang, X.L. Zhu, Z.P. Chen and J. Zhu, J. Polym. Sci. A: Polym. Chem., 43, 2358 (2005). 